\title{
Using Creative Thinking in Defining Geometry Concepts via Recognizing Elementary Objects, Drawing, and Writing Process of Concept Image
}

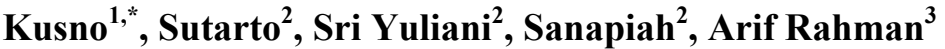 \\ ${ }^{1}$ Department of Mathematics, Faculty of Mathematics and Sciences, University of Jember, Indonesia \\ ${ }^{2}$ Faculty of Sciences Technology and Applications, Universitas Pendidikan Mandalika, Indonesia \\ ${ }^{3}$ Faculty of Culture Management and Business, Universitas Pendidikan Mandalika, Indonesia
}

Received April 24, 2021; Revised June 5, 2021; Accepted June 25, 2021

\section{Cite This Paper in the following Citation Styles}

(a): [1] Kusno, Sutarto, Sri Yuliani, Sanapiah, Arif Rahman, "Using Creative Thinking in Defining Geometry Concepts via Recognizing Elementary Objects, Drawing, and Writing Process of Concept Image," Universal Journal of Educational Research, Vol. 9, No. 7, pp. 1395 - 1408, 2021. DOI: 10.13189/ujer.2021.090706.

(b): Kusno, Sutarto, Sri Yuliani, Sanapiah, Arif Rahman (2021). Using Creative Thinking in Defining Geometry Concepts via Recognizing Elementary Objects, Drawing, and Writing Process of Concept Image. Universal Journal of Educational Research, 9(7), 1395 - 1408. DOI: 10.13189/ujer.2021.090706.

Copyright $\bigcirc 2021$ by authors, all rights reserved. Authors agree that this article remains permanently open access under the terms of the Creative Commons Attribution License 4.0 International License

\begin{abstract}
Mathematics teacher's competences in understanding some properties and relationships between the elements of geometry objects support the students' learning in mastering the geometry contents. This research investigates and describes the creative thinking approach of teacher candidates in defining geometry concepts based on recognizing primitive and elementary objects, drawing, and writing process of concept image. The steps are as follows. Using pre-test, we evaluated the students who had a good basic knowledge of geometry to attend a geometry course. We provided seven geometry definitions to encourage the students to understand. Then, they were tested and ranked by their understandings of the seven definitions with passing grade minimum score sixty of interval 0-100. From the qualified students, they do the task to compose some alternative definitions of these concepts through the creative thinking scheme. We interviewed them to know the understanding process. This research found that students' creativity offers many ideas and ways to construct diverse alternative definitions. It included understanding pre-knowledge, the essential features needed to build the geometry concepts, and structuring definition language. We discovered three group types of creative thinking result in the defining geometry concepts, i.e., productive-creative, constant-creative, and decrease-creative thinking. This research contributes
\end{abstract}

knowledge for students about how geometry definitions are constructed by introducing primitive and elementary objects of geometry, sketching concepts image, and writing practice of the concepts. The creative thinking scheme can guide and lead students to state the geometry definitions in both descriptive and connotative expressions with different sentences.

Keywords Creative Thinking, Elementary Objects, Drawing-Writing Process, Alternative Definitions, Concept Image

\section{Introduction}

To help the students in understanding mathematics, the teachers then should be mastering concepts and skills in mathematics teaching. In geometric learning, they need geometrical thinking competencies, i.e., figural (to model, conjecture, define), visual (observation, exploration), operational, and reasoning (argumentation, deductive) [1], due to the geometric thinking was concerned with how people reason applying the properties of geometry figures (pictures, shapes) and spatial relationships. We have to describe spatial relationships involving properties of form, 
space, and position. Using geometry learning could allow students to develop their creative problem solving and reasoning skills [2]. These competencies of teachers will support the students in mastering the geometric contents, i.e., the students can identify and discuss the relationships between the properties of different shapes when they define some geometry objects. They can develop their logical arguments with these definitions and axioms in the deductive method to prove some geometry theorems.

According to the data analysis of national examination competencies of teachers in 2015 in Indonesia, the primary value of achievement was 53.02, while the government expectation was 55. Also, the average position of the professional and pedagogical value was at 54.77 and 48.94 , i.e., in fail categories. In 2016, the teachers' competencies were 66.45 , i.e., in the satisfactory class [3]. The data of UNESCO from the Global Education Monitoring (GEM) reported in 2016 concerning education in Indonesia only ranked 10th out of 14 developing countries. Teachers ranked 14th out of 14 developing countries in the world [4].

The lack of teachers' mathematics mastery affected the lack of students' mathematical understanding. Based on the results of tests and evaluations of the Program for International Student Assessment (PISA) in 2015 by the Organization for Economic Cooperation and Development (OECD), the ability of Indonesian students was relatively low. The average score achieving for Indonesian students was in position 62 from 70 countries, i.e., science, reading, and mathematics; it was ranked 62, 64, and 63 of 70 evaluated countries. The rating and the average score of Indonesian students did not look much different from the results test of the 2012 PISA, which was in the low mastery category [5]. PISA contains geometry subjects from several tested subjects, including space and shape (geometry), change and relationships, quantity, and uncertainty [6]. It meant that the mastery of the students in the geometry field was also still low. In implementing the 2016 national exam for measuring competency achievement, the mathematics subjects in junior high school experienced the most significant decline, namely from an average score of 56.28 in 2015 to 50.24 . For this reason, the government tried to introduce questions for encouraging the creative thinking of students, i.e., critical thinking and reasoning thinking $[7,8]$. Then in 2019 , it was also an average score decline of 46.8. In answering geometry and trigonometry test, students of senior high school were only correct responses $37 \%$ in 2017 and $34 \%$ in 2018; meanwhile, in 2019, the mathematics test score (algebra, geometry, calculus, statistics) was a low result of 39.37 [9].

Based on the information, the mathematics teacher candidates should improve their competencies in number, algebra, geometry, measurement, data analysis and probability. Notably, in geometry, teacher candidate's students of mathematics need to practice and build their visual and figural abilities. Using these competencies, they can develop geometry concepts and definitions precisely and correctly. They become capable of utilizing these definitions and axioms to prove the geometry theorems. In the future, the teacher will be skilled in applying it to geometry learning for their students in the class.

\section{State of the Art}

Most of students have difficulty in defining a geometry object using standard language or their own words as an alternative definition in descriptive or connotative form. The research results that involved 12th-grade students in senior high schools in Israel reported three types of students' arguments relating to definitions. It needed justifications involving logical concerns, communicative considerations, and figurative considerations. Furthermore, Zaslavsky and Shir [10] stated that, in the geometry field, the dominant kind of reasoning was definition-based reasoning. Other research introduced the definitions of geometry figures involving 53 school students of 9th grade. Via "Quadrilateral Game", they were occupied with generating figures to meet some stipulated properties rather than describing. The game might help create a context for discussion about definitions and engage students with figures in a different way than usual [11].

To stimulate the students should be actively engaged in defining geometry concepts, De Villiers [12] presented some data relating to a teaching experiment aimed at developing students' ability to construct the definitions. Implementing Van Hiele level's approach, he evaluated that composing constructive and descriptive definitions became an economic definition. Pedagogical Education's students about the similarity of geometry shapes introduced specific structures dealing with the geometry concepts based on the school instruction. In this study, a large percentage of the students were not able to correctly define the similarity of shapes and the intuition for affecting their responses and mathematical achievement [13]. Research on elementary pre-service teachers assessed their ability to answer some questions involving geometry concepts. Using both graphic organizers and concept attainment teaching strategies improved the performance in the post-test. The challenging geometry concepts for the students were needed so that pre-service teachers would be able to provide their students with increased conceptual understanding [14]. Salinas [15] stated that the field of geometry, with its well-defined van Hiele levels and varied uses of definition, could provide a concrete foundation for exploring both teachers' instructional practices and student learning. Yadav [16] concluded the exact definition of mathematics as studying assumptions, properties, and applications. In teaching and assignments, it should maintain the order of assumptions, 
properties, and applications to get the desired aim of teaching mathematics.

We can sum up the research reviews as follows. First, pictures have been utilized as a tool to define the geometry concepts by involving the students, but the introduced methods are not yet optimal to how they can generate the whole substantial properties to define the geometry concepts. Second, the introduction studies still lack information about the students' difficulty level in structuring definition sentences that fulfill the definition criteria. Therefore, it still has many more opportunities for further researchers to conduct a study relevant to the students' skills in defining geometry concepts. It is essential for teacher candidate's students that can effectively and creatively structure several alternative definitions in a different way to express a geometry concept. Besides, this geometry concept is usually only exposed in one type of formal definition, taken directly from a textbook. Using some primitive and elementary objects of concept images visually is expected to help and involve them in the process of defining a geometry concept correctly.

\section{Purposes and Problems of Research}

Defining a geometry concept requires some criteria. The definition must be stated the essential properties of the defined concept; it is not too wide or narrow, and it cannot be negative. It must use a definite statement, explicit, simple, appropriate, and avoid metaphor. The formed definition can be in terms of a descriptive or connotative sentence. The descriptive definition affirms the concept according to the essential characteristics and meets the necessary and sufficient conditions. In the connotative definition, we define the geometry concept by stating its group (genus) and the differentiator.

Generally, defining a word is more abstract than defining the concept aided by the geometry pictures visually. For this reason, the objectives of this research are to encourage students' creative thinking and involve them to be competent in constructing some alternative definitions for a given formal concept via the geometry figures. In this case, we conduct the process from the intuitive term to the formal definition through the creative thinking scheme approach in the following steps. The students identify a geometry concept image to recognize the primitive and elementary objects (we call elements) of geometry. Then, they utilize these identified geometry elements to draw the concept image. Hereafter, they must write the ways or steps to construct this picture to understand the image characteristics with their own language. Then, they structure some alternative definitions with their own words in the form of descriptive or connotative definitions. The definitions meaning is equivalent to the given formal definition known before.
From these constructed definitions, we do not evaluate the truth and error according to the defined criteria; but, rather than we value their achievement level in finding the geometry characteristics of the created definitions that meet the necessary and sufficient criteria. Applying this definition construction scheme, the problems of the research are as follows.

(a) How do the teacher candidates creatively recognize various geometry elements of formal concept images and employ them to draw and write the geometry concept definitions in different ways (descriptive or connotative manner)?

(b) How can these students achieve the alternative definitions that meet the necessary and sufficient criteria through the activities of the creative thinking scheme?

Contributions to the literature are as follows.

(a) This study contributes knowledge for students about how geometry definitions are constructed by introducing primitive and elementary objects of geometry, sketching concepts image, and writing practice of the concepts.

(b) The study shares new findings related to the creative thinking scheme that can guide and lead students to state the geometry definitions in both descriptive and connotative expressions.

(c) This research emphasizes using a creative thinking approach to encourage students of teacher candidates and involve them in defining formal geometry concepts into several alternative definitions with different sentences.

\section{Framework of Research}

In teaching and learning practice, defining geometry concepts applies a lot using visual figures. However, to find the specific essential properties of a geometry concept different from any others according to the shape and the measure of a given picture is not simple and easy. The students must be willing to commit to more than one idea and must try to achieve the way to create the definitions. They have to be brave enough to produce all possible alternative definitions. For this reason, this paper proposes a creative thinking approach to help them in obtaining both minimal and maximal data of the essential elements of the geometry image. We utilize them to construct the definitions of the concepts. First, we adopt the theory, and the research finding refers to the parts and the creative thinking models for which their procedures close to the way to construct the geometry definitions. Second, we introduce the practical scheme to obtain some new alternative definitions with different sentences in which its content is equivalent to the provided formal concepts. The description of those is as follows.

There are some theories and previous researches that 
already introduced in developing the way of students creative thinking. Chamberlin and Moon [17] stated that creative students might apply multiple modes and intelligence to solve the problems, while students with limited creativity might be seeking the "quick-fix" solution. Koloroutis [18] and Harris [19] introduced creative thinking as a kind of thinking that focused on exploring ideas, generating possibilities, looking for many right answers rather than just one. The characteristics of creative thinking were generative, divergent, lateral, possibility, suspended judgment, diffuse, subjective, an answer, right brain, visual, associative, richness, novelty, and yes. Meanwhile, in the personal creative aspect, they called the attitudes: curious, seeks problems, enjoys challenges, optimistic, able to suspend judgment, comfortable with imagination, sees problems as opportunities, sees problems as attractive, problems are emotionally acceptable, challenges assumptions, and it doesn't give up easily: perseveres works hard. On the other hand, the characteristics of creative thinking could be summarized as well: flexibility, authenticity, multiple thinking, wondering, thinking fast and independent, being open to criticism, rationalism, being suspicious, to come up with different solutions, to realize and define the problem $[20,21]$.

In terms of research finding in mathematics education, Nakin [22] recommended that creativity and divergent thinking activities be utilized in teaching and learning geometry using the problem-centered approach. These activities enhance conceptual understanding and group-work during the learning process. Then, Dan and Xie [23] reported a strong positive correlation between the students' mathematical modeling skills and their creative thinking levels. Meanwhile, Nadjafikhah et al. [24] suggested that creative teachers and creative environments could train creative students. Therefore, creative thinking and environments are considered some of the necessities. Grégoire [25] found that mathematics education teachers should begin mathematical creativity at school. They had to develop their original thinking by providing the opportunity to work with ill-posed and open-ended problems, to go wrong and make mistakes, and to find different solutions to the same issues. In terms of research finding in mathematics education, Nakin [22] and Sheffield [26] quoted in Pantazi et al. who studied the mathematical creativity based on four aspects from the idea of Rhodes [27], i.e., product (the communication of a unique, novel and valuable idea or concept), person (as a human being: cognitive abilities, personality traits, and biographical experiences), process (operating in creating an idea: the methodology), and press (the relationship between human beings and their environment). They considered those factors to enhance mathematical creativity. The cognitive characteristics might empower the creative ability, and the sub-processes students follow to find different and original solutions. The awareness of it would provide teachers and educators with "educational equipment" regarding the dimensions they should invest in during their ongoing lessons.

Concerning these several theories and researches perspectives about creative thinking in educational mathematics, the discussion of this paper focuses on developing and identifying an unusual ability of students to create several new alternative definitions of given geometry concepts. This research inspects process and investigates relevant and possible personal cognitive aspects to develop the alternative definitions of geometry concepts, i.e., generative, visual, subjective, divergent, lateral, richness, and novelty. We evaluate these cognitive aspects to know students' understanding progress in defining process of geometry concepts. Visual and generative thinking aspect [VGT] is used to investigate how much students can recognize elements of geometry for constructing concept images. Subjective and divergent thinking [SDT] is conducted to measure the students' competencies in drawing and understanding the features and characteristics of the picture. The elements of lateral, richness and novelty thinking [LRNT] are to objectively asses the students' writing in descriptive and connotative definitions. This definition process that is elaborated by the students from the textbooks to the alternative definitions is ordered in the following stages (Figure 1). First, we introduce to the students some geometry concepts' formal definitions taken from textbooks. Second, via concept image of the given formal definitions, they analyze to make a list of primitives and elementary objects of geometry needed to design the image. Third, from these primary objects, they conduct various experiments to draw and write how to reconstruct the concept image. Finally, for each given concept, the students arrange some alternatives definitions. We assess their work results will equivalently be toward the formal definitions of the textbooks.

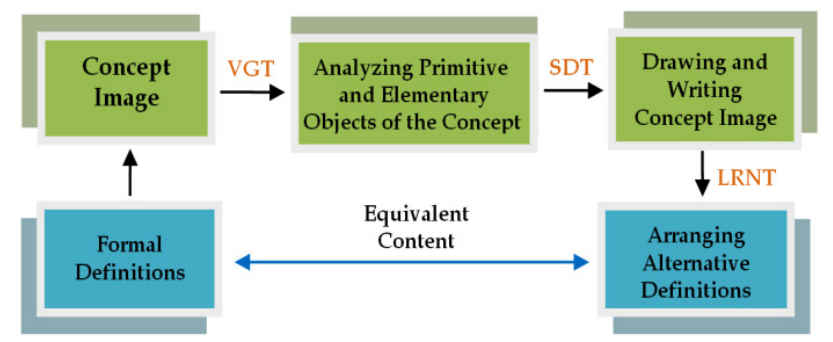

Figure 1. Composition of alternative definitions using creative thinking scheme

\section{Method}

This research adopts a qualitative descriptive approach to describe a phenomenon and its characteristics with naturalistic (real) data [28]. The motivation of the study was to investigate and describe: first, the number of students could recognize some elements of geometry used 
to construct a geometry concept image; second, the competencies of students could improve in sketching and understanding the features of the concept image through these elementary geometry objects' data; third, the competencies of students progressed in writing descriptive and connotative definitions in finding some alternative definitions of the geometry concepts.

\subsection{Participants and Times}

The research involved 70 undergraduate students selected from 111 participants prepared to be junior and senior high school teacher candidates from a mathematics education department of an excellent private university in Mataram, NTB Province, Indonesia. Then, based on the seven geometry definitions tested on the 70 students, it got 28 qualified research participants. The research was undertaken during semesters 1 and 2, the college year 2019-2020.

\subsection{Instruments}

The research instruments consisted of the geometry course material containing seven geometry definitions (Definition 1-7) and the undergraduate students' test questions (Appendix 1). Then, it arranged some geometry elements of the seven formal definitions (Appendix 2) to assess the students' work results in identifying and sketching concept images. The alternative definitions instrument in Section 5.4 is applied to evaluate the content equivalency between the alternative definitions of student work results toward the textbooks' formal definitions.

\subsection{Procedure of Research}

Using pre-test, from one hundred and eleven students, it was selected seventy students to attend a geometry course. These seventy students were separated into two classes, with each class 35 students. In initial conditions, the students were given the course material about primitive terms, and seven formal definitions of the topics: incidence axioms of line and angle, the congruence of line and angle, and triangle congruencies referred to some geometry textbooks $[29,30,31,32]$. Improving students for understanding primitive and primary objects of seven definitions, the lecturer provided explanations and demonstrations about how to draw a ray, a segment, an angle, a triangle, an altitude, a median, and an angle bisector of a triangle shown in Figure 6 and Figure 7 of the Appendix 1-A. Then, using item questions in Appendix 1-B examined both student groups for measuring their comprehension level of Definition 1-7. Evaluating examination results of both classes, we ranked and randomly elected the students as much as $60 \%$ that met the passing grade and proportionally represented the rank values of low, middle, and high-level grade. For ensuring students who have understood in these seven definitions, the score criterion of the passing grade was a minimal 60 of interval score $0-100$. In this case, we got 28 qualified research participants with the names $A$ up to $A B$ shown in Table 1. Applying the creative thinking scheme in Figure 1, these students were given a task to learn in the following stages.

(a) They analyzed all primitive and elementary objects needed to design the given formal Definitions 1-7. Via Appendix 2, we provided a score for the number of completed student work's frequencies which were listed in the first row of Table 1.

(b) Applying the geometry elements of activities (a), they tried to draw and wrote the methods or the steps for reconstructing the concept image of the Definitions 1-7. In this case, evaluating the students' writing description toward the reference in Appendix 2, we scored the declaration types of the concept construction's methods made by the students. The concept image stated in descriptive form and explained by these elementary geometry objects was labeled M1. Another type was declared in a connotative way by using geometry maximal/general data (genus) and differentiator, and we labeled M2. Outside of both types, we noted ED (External-Definitions). The frequencies score M1, $\mathrm{M} 2$, and ED of the students' task results were listed in the second, third, and fourth row of Table 1.

(c) The students arranged some alternative definitions for Definitions 1-7 of the textbooks. Then, we interviewed to know their understanding process. Afterthat, we were evaluating contents equivalencies of the created alternative definitions toward Definitions 1-7. The alternative definitions' content value was in intervals 0 up to 5 . Besides, it calculated the number of frequencies of alternative definitions made by each student and scored the frequency which he/she was successful in stating these alternative definitions. The content's score of the alternative definitions, frequency, and worthiness of each student's work results was evaluated using the alternative definitions' instrument D1a up to D7b in Section 5.4. The students' outcomes values list was in Table 2. When there were results outside of this evaluation; we provided a score in the row noted EAD (External-Alternative Definitions) in Table 2.

\subsection{Some Alternative Definitions Associated with the Seven Geometry Formal Concepts}

Based on the geometry data in Figures 8-9 of Appendix 2 , we structure some alternative definition sentences that their meanings are equivalent and approach to Definitions 1-7. In this case, when the students can find the alternative definitions outer of the list, these definitions are called alternative external definitions (EAD in Table 2).

Definition 1: The ray $\overrightarrow{A B}$ is

(a) a set of points that consist of the endpoint $A$, the point $B$, the points between $A$ and $B$, and all points on the 
same side of the point $B$, but the side does not contain the point $A$;

(b) a set of points on the line $\overleftrightarrow{A B}$ that contain endpoint $A$ and all points on the same side of point $A$ that has point $B$;

(c) a part of a straight line $\overleftrightarrow{A B}$ beginning at point $\mathrm{A}$ and extending limitlessly in one direction from point $A$ to the point $B$.

\section{Definition 2: The line segment $\overline{\boldsymbol{C D}}$ is}

(a) a set of points on the line $\overleftrightarrow{C D}$ that are drawn from point $C$ to point $D$;

(b) a set of points on the ray $\overrightarrow{C D}$ that contain point $C, D$, and all points between points $C$ and $D$;

(c) a set of points on the line $\overleftrightarrow{C D}$ that contain points $C, D$, and all points between points $C$ and $D$.

Definition 3: The angle $\angle C A B$ is

(a) a set of points generated by three different points $A, B$, $C$ are drawn two rays $\overrightarrow{A C}$ and $\overrightarrow{A B}$;

(b) a set of points constructed by the ray $\overrightarrow{A C}$ and the ray drawn from the endpoint A to point B, i.e., the ray $\overrightarrow{A B}$;

(c) a set of points that are the union of the ray $\overrightarrow{A C}$ and $\overrightarrow{D B}$ in which the point $D$ meets at the endpoint $A$;

(d) a set of points that are the union of two rays $\overrightarrow{A C}$ and $\overrightarrow{D B}$ contained by the line $\overleftrightarrow{D B}$, and the point $D$ meets at the endpoint $A$;

(e) a set of points that are the union of two rays $\overrightarrow{A C}$ and $\overrightarrow{D B}$, respectively, is contained by the lines $\overleftrightarrow{A C}, \overleftrightarrow{D B}$, and the point $D$ meets at the endpoint $A$.

Definition 4: The triangle $A B C$ is

(a) a union of three segments $\overline{A B}, \overline{B C}$ and $\overline{C A}$, respectively, constructed by three non-collinear different points $A, B$, and $C$;

(b) a union of a segment $\overline{C B}$, and two segments are drawn from the point $\mathrm{A}$ in outer and not align with the piece $\overline{C B}$ to both endpoints of the segment $\overline{C B}$;

(c) a union of three segments $\overline{A B}, \overline{A C}$ and $\overline{C B}$ with the length measure of any line segment less than the sum length measure of the others by uniting vertexes of pairs segments precisely at points $A, B, C$;

(d) a union of the angle $\angle \mathrm{CAB}$ constructed by the legs segment $\overline{A B}$, and $\overline{A C}$, and the segment $\overline{B C}$ that is drawn from points $B$ to $C$.

Definition 5: The altitude $C D_{1}$ of the triangle $A B C$ is

(a) a segment drawn from the vertex $\mathrm{C}$ of the triangle $A B C$ to the point of the intersection between a line passes at the point $\mathrm{C}$ and perpendicular to the opposite side $\overline{A B}$ of the triangle $\mathrm{ABC}$, i.e., the point $\mathrm{D}_{1}$;

(b) a segment drawn from the intersection point between a line that passes the vertex $\mathrm{C}$ and perpendicular to the opposite side $\overline{A B}$ of the triangle $A B C$, i.e., the point $D_{1}$, to the vertex $C$.
Definition 6: The median $C D_{2}$ of triangle $A B C$ is a segment drawn from the midpoint of the side $\overline{A B}$ of the triangle $A B C$, i.e., the point $D_{2}$, to the vertex $C$.

Definition 7: The angle bisector $C D_{3}$ of triangle $A B C$ is

(a) a segment drawn from the vertex $C$ to the intersection point between the line of the angle bisector $\angle A C B$ and the side $\overline{A B}$ of the triangle $A B C$, i.e., the point $D_{3}$;

(b) a segment drawn from the intersection point between the line of the angle bisector $\angle A C B$ and the side $\overline{A B}$, i.e., the point $D_{3}$, to the vertex $C$ of the triangle $A B C$.

\section{Results and Discussion}

Table 1 shows that the students of a passing grade more than or equal 60 scores could produce about ten geometry elements of concepts image to the seven given definitions. It consisted of about nine pictures for the descriptive definitions (M1) and one picture for the connotative definition (M2). The students named M and AA already achieved the maximal frequencies of finding primitive and elementary objects of geometry. They could discover 15 figures from 17 figures that are presented in Figure 8 and Figure 9. In contrast, the students of minimal frequencies only found five pictures. On the other hand, the maximal frequencies of composing descriptive definitions named $\mathrm{M}$ and AA while structuring connotative definitions were named $\mathrm{A}$ and $\mathrm{T}$. The students produced no figure beyond those 17 figures list.

In general, the students creatively could recognize and introduce each given geometry concept's primitive and essential objects in more than one picture. Furthermore, applying the pictures, it could not only use in descriptive definitions but also could be employed in connotative definitions that met the necessary and sufficient criteria in defining the concept. The results mean that when the students were given a geometry concept, they could introduce at least one new alternative definition of the concept. The creative efforts to identify basic elements of geometry used to define a geometry concept via concept image would encourage the teacher candidate's students to be competent in obtaining various main features. This manner was very constructive and straightforward for defining concepts presented in different communication languages. These facts were in line with the review results of mathematical creativities. It had a relation with the product, the person, the process, and the press [26,27], then, the visual pictures or images and the figural concepts would interact in the cognitive activity of a person (a child or an adult) sometimes linear or different in other situations [33]. The creative efforts led the students to be aware and focus on exploring ideas, generating possibilities, and looking for many correct answers. Hereafter, they became generative and divergent thinking and novelty ideas $[18,19]$. 
Table 1. Students' achievement in finding elementary objects

\begin{tabular}{|c|c|c|c|c|c|c|c|c|c|c|c|c|c|c|c|c|c|c|c|c|c|c|c|c|c|c|c|c|c|c|}
\hline \multirow{2}{*}{ Frequency } & \multicolumn{28}{|c|}{ Name of Students } & \multirow[b]{2}{*}{$\Sigma$} & \multirow[b]{2}{*}{ Mean } \\
\hline & $\mathbf{A}$ & B & $\mathbf{C}$ & $\mathbf{D}$ & $\mathbf{E}$ & $\mathbf{F}$ & $\mathbf{G}$ & $\mathbf{H}$ & I & $\mathbf{J}$ & $\mathbf{K}$ & $\mathbf{L}$ & $\mathbf{M}$ & $\mathbf{N}$ & $\mathbf{O}$ & $\mathbf{P}$ & $\mathbf{Q}$ & $\mathbf{R}$ & $\mathbf{S}$ & $\mathbf{T}$ & $\mathbf{U}$ & $\mathbf{V}$ & $\mathbf{W}$ & $\mathbf{X}$ & $\mathbf{Y}$ & $\mathbf{Z}$ & $\mathbf{A A}$ & $\mathbf{A B}$ & & \\
\hline Elementary Objects & 14 & 8 & 7 & 9 & 9 & 10 & 9 & 5 & 9 & 11 & 10 & 7 & 15 & 8 & 14 & 9 & 6 & 12 & 14 & 14 & 12 & 10 & 8 & 8 & 9 & 8 & 15 & 7 & 277 & 9.89 \\
\hline M1 & 10 & 5 & 7 & 7 & 7 & 7 & 7 & 5 & 7 & 9 & 7 & 7 & 15 & 8 & 14 & 9 & 6 & 12 & 14 & 10 & 11 & 8 & 8 & 8 & 9 & 8 & 15 & 7 & 247 & 8.82 \\
\hline M2 & 4 & 3 & 0 & 2 & 2 & 3 & 2 & 0 & 2 & 2 & 3 & 0 & 0 & 0 & 0 & 0 & 0 & 0 & 0 & 4 & 1 & 2 & 0 & 0 & 0 & 0 & 0 & 0 & 30 & 1.07 \\
\hline ED & 0 & 0 & 0 & 0 & 0 & 0 & 0 & 0 & 0 & 0 & 0 & 0 & 0 & 0 & 0 & 0 & 0 & 0 & 0 & 0 & 0 & 0 & 0 & 0 & 0 & 0 & 0 & 0 & 0 & 0 \\
\hline
\end{tabular}

Table 2. Students' achievement profile to arranging alternative definitions

\begin{tabular}{|c|c|c|c|c|c|c|c|c|c|c|c|c|c|c|c|c|c|c|c|c|c|c|c|c|c|c|c|c|c|c|}
\hline \multirow[b]{2}{*}{$\begin{array}{l}\text { Alternative } \\
\text { Definitions }\end{array}$} & \multicolumn{28}{|c|}{ Name of Students } & \multicolumn{2}{|c|}{ Frequency } \\
\hline & $\mathbf{A}$ & B & $\mathbf{C}$ & D & $\mathbf{E}$ & $\mathbf{F}$ & G & $\mathbf{H}$ & I & $\mathbf{J}$ & $\mathbf{K}$ & $\mathbf{L}$ & $\mathbf{M}$ & $\mathbf{N}$ & $\mathbf{O}$ & $\mathbf{P}$ & $\mathbf{Q}$ & $\mathbf{R}$ & $\mathbf{S}$ & $\mathbf{T}$ & $\mathbf{U}$ & $\mathbf{v}$ & W & $\mathbf{X}$ & $\mathbf{Y}$ & $\mathbf{Z}$ & $\begin{array}{l}\mathbf{A} \\
\mathbf{A}\end{array}$ & $\begin{array}{l}\mathbf{A} \\
\mathbf{B} \\
\end{array}$ & $\Sigma$ & $\begin{array}{c}\text { Pass } \\
\text {-ed }\end{array}$ \\
\hline D1a & & & & & 1 & & & & & & 3 & & 3 & 5 & 5 & 5 & 5 & 4 & 2 & 3 & 3 & 3 & 4 & 4 & 3 & 2 & 2 & 3 & 18 & 14 \\
\hline D1b & 5 & 5 & 2 & 5 & & 5 & 2 & 2 & 5 & 5 & & 2 & & & & & & & & 3 & & 3 & & & & & & & 12 & 8 \\
\hline D1c & & & & & & & & & & & & & & & & & & & & & & & & & & & & & 0 & 0 \\
\hline D2a & 5 & 5 & 4 & 5 & 2 & 2 & 5 & 3 & 5 & 5 & 2 & 2 & 3 & 3 & 5 & 4 & 4 & 2 & 3 & 2 & 3 & 4 & 3 & 3 & 2 & 3 & 3 & 3 & 28 & 21 \\
\hline $\mathrm{D} 2 \mathrm{~b}$ & 2 & & & 3 & 2 & 2 & & & & & & & & & & & & & & 2 & 3 & 3 & & & & & & & 7 & 3 \\
\hline $\mathrm{D} 2 \mathrm{c}$ & 2 & & & & & 2 & & 2 & & & 2 & & & & & & & & & & & & & & & & & & 4 & 0 \\
\hline D3a & 5 & & & & & & & & & & & & & & & & & & & & & & & & & & & & 1 & 1 \\
\hline D3b & 2 & & & & & & 2 & & & & & & & & & & & & & 2 & & 4 & & & & & & & 4 & 1 \\
\hline D3c & & 5 & 2 & 2 & 3 & 4 & 3 & 3 & 4 & 5 & 3 & 2 & 3 & 5 & 5 & 4 & 4 & 2 & 4 & 2 & 3 & 4 & 3 & 3 & 3 & 3 & 3 & 3 & 27 & 22 \\
\hline D3d & 2 & & & 2 & & & 2 & & & & & & & & & & & & & & & & & & & & & & 3 & 0 \\
\hline D3e & 2 & & & 2 & & & 2 & & & & & & & & & & & & & & & & & & & & & & 3 & 0 \\
\hline $\mathrm{D} 4 \mathrm{a}$ & 5 & 5 & & 5 & 3 & 5 & 5 & 4 & 5 & 5 & 2 & 5 & 3 & 5 & 4 & 3 & 5 & 2 & 4 & 2 & 3 & 3 & 3 & 3 & 1 & 3 & 3 & 3 & 27 & 23 \\
\hline $\mathrm{D} 4 \mathrm{~b}$ & & & & 2 & 1 & & & & & & & & & & & & & & & 2 & & 3 & & & & & & & 4 & 1 \\
\hline $\mathrm{D} 4 \mathrm{c}$ & & & 3 & 2 & & & & & & & 3 & & & & & & & & & & & & & & & & & & 3 & 2 \\
\hline D4d & & & & & & & & & & & & & & & & & & & & & & & & & & & & & 0 & 0 \\
\hline D5a & 5 & & 4 & 5 & 5 & 5 & 5 & & 5 & 5 & 5 & 5 & 5 & 5 & 5 & 3 & 4 & 2 & 4 & 2 & 3 & 2 & 3 & 3 & 3 & 3 & 3 & 3 & 26 & 23 \\
\hline D5b & & & & & & & & 4 & & & & & & & & & & & & 2 & & & & & & & & & 2 & 1 \\
\hline D6 & 5 & & 2 & 3 & 4 & 5 & 5 & 3 & 5 & 5 & 4 & 5 & 5 & 5 & 5 & 3 & 5 & 2 & 4 & 2 & 3 & 3 & 4 & 3 & 1 & 1 & 3 & 3 & 27 & 22 \\
\hline D7a & 5 & & 1 & 5 & 2 & 5 & 5 & & 5 & 3 & 5 & 5 & 5 & 5 & 5 & 3 & 5 & 2 & 4 & 2 & 3 & 3 & 4 & 2 & 3 & 1 & 3 & 3 & 26 & 20 \\
\hline $\mathrm{D} 7 \mathrm{~b}$ & & & & & & & & 1 & & & 2 & & & & & & & & & 2 & & & & & & & & & 3 & 0 \\
\hline$\Sigma$ & 45 & 20 & 18 & 41 & 23 & 35 & 36 & 22 & 34 & 33 & 31 & 26 & 27 & 33 & 34 & 25 & 32 & 16 & 25 & 28 & 24 & 35 & 24 & 21 & 16 & 16 & 20 & 21 & 225 & 162 \\
\hline $\begin{array}{l}\text { Mean } \\
\text { Score }\end{array}$ & 3.8 & 5.0 & 2.6 & 3.4 & 2.6 & 3.9 & 3.6 & 2.8 & 4.9 & 4.7 & 3.1 & 3.7 & 3.9 & 4.7 & 4.9 & 3.6 & 4.6 & 2.3 & 3.6 & 2.2 & 3.0 & 3.2 & 3.4 & 3.0 & 2.3 & 2.3 & 2.9 & 3.0 & Mean & $=3.45$ \\
\hline $\begin{array}{l}\text { Alternative } \\
\text { Definitions } \\
\text { Number }\end{array}$ & 12 & 4 & 7 & 12 & 9 & 9 & 10 & 8 & 7 & 7 & 10 & 7 & 7 & 7 & 7 & 7 & 7 & 7 & 7 & 13 & 8 & 11 & 7 & 7 & 7 & 7 & 7 & 7 & Mean & $=8.04$ \\
\hline EAD & 0 & 0 & 0 & 0 & 0 & 0 & 0 & 0 & 0 & 0 & 0 & 0 & 0 & 0 & 0 & 0 & 0 & 0 & 0 & 0 & 0 & 0 & 0 & 0 & 0 & 0 & 0 & 0 & 0 & 0 \\
\hline Evaluation & Crit & ia of & efini & & & & & & & & & & & & & Scol & & & & & & & & & & & & & & \\
\hline a. Adequac & of $u$ & ng pri & nitive & elem & ary ob & cts o & geom & & & & & & & & & 1. If & 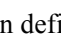 & ition & nly & $\mathrm{eco}$ & at $(a$ & . & & & & & & & & \\
\hline b. Accurac & of d & ermin & ng the & lation & tween & geom & ry obj & & & & & & & & & 2. If & $n$ defi & iition & the $\mathrm{c}$ & tent (a & ) and & b) writ & & & & & & & & \\
\hline c. Accurac & of de & ermin & ag pos & on \& & ection & f geo & netry $\mathrm{c}$ & bjects; & & & & & & & & 3. If & n defi & iition, & the $c$ & tent (a & , (b), & and (c) & writte & & & & & & & \\
\hline d. Accurac & in ar & nging & word & operl & & & & & & & & & & & & 4. If & $n$ defi & iition, & the co & tent (a & , (b), & (c), anc & (d) $\mathrm{w}$ & ritten; & & & & & & \\
\hline e. Accurac & in ch & osing & vords & & & & & & & & & & & & & 5. If & $n$ defi & ition, & the co & tent (a & ), (b), & (c), (d) & , and ( & e) writt & & & & & & \\
\hline
\end{tabular}


Students' achievement profile in arranging alternative definitions of these seven concepts is presented in Table 2. The student's achievement level in defining the geometry concepts arrived at the maximal score totals 45 of the names A with an average score of 3.8. The minimal score counts 16 named R, Y, and $\mathrm{Z}$ with an average score of 2.3. From the 28 students, the achievement level average was 3.45 of interval $0-5$ or scored 69 of range $0-100$ in the category almost perfect. The quality contents of the students' alternative definitions for Definitions 1 - 7 practically have achieved very well. It was natural because the creative thinking skills approach involved finding many possible answers rather than one, and they might contain the seeds of something potentially helpful or making mistakes [34].

For each student, he/she could achieve success about eight alternative definitions, and it found no statement of words beyond these alternative definitions (EAD in Table 2). The student's creativity to discover the primary elements of geometry, sketching, and writing process for concept image provide many ideas, ways, and more effective ways to construct alternative definitions. Furthermore, the students define some geometry concepts; generally, they preferred to choose the simple data's easy words.

There were 18 alternative definition types composed by 28 students relative to twenty definition types D1a up to $\mathrm{D} 7 \mathrm{~b}$ in Section 5.4. From the 18 constructed definitions, there are the correct 14 definition types as shown in the last column of Table 2 . The definition types composed by students more than five times are D1a, D1b, D2a, D2b, D3c, D4a, D5a, D6, and D7a (Table 2 and Figure 2). The students can structure 225 alternative definitions, and from these results, there are 162 definitions $(72 \%)$ correct, i.e., their content is equivalent to the tested seven definitions by passing grade score 3 of interval 0-5.

Applying the creative thinking scheme, generally, each participant could recognize about ten elementary objects of geometry through the concept images for redefining the seven given geometry definitions by using their words in the different sentences. Each student could structure nine descriptive definitions and one connotative definition to these elements of geometry and the sketched pictures. From these definitions result, every student could produce about six alternative definitions in an accurate understanding. Overall, these results indicated some increases of the students' skills in defining geometry concepts. It included understanding pre-knowledge, the essential features needed to construct the geometry concepts, and in structuring language of the definitions.

In Table 1, we find the average student works in creating the main elements of the concepts image about ten figures. However, in Table 2, they can produce only about six correct definitions of 8 alternative definitions made. From the data, some students can compose the alternative definitions employing almost all elementary objects and sketched pictures, but, on the other hand, the students may still be confused to structure the definitions by using these data with correct sentences. The participants of this category fail to define the geometry concept. This students' fail case is in line with Fischbein's thinking that the figural concepts were mental entities of abstract ideal (geometrical figures). It cannot be found in reality [32]. As a result, some students had difficulty composing the definition. To achieve the interaction between the perception and the mental level, the usage of geometry images (pictures) is suggested as necessary as possible to avoid the complexities in teaching and learning concepts [35].

Analyzing Table 1 against Table 2, we get three group types of undergraduate students' creative thinking effects in defining geometry concepts based on their achievement in finding the essential elements and properties of geometric figures, i.e., productive-creative thinking, constant-creative, and decrease-creative thinking. Productive-creative thought occurs when a student can produce alternative definitions more than the number of elementary geometry objects or pictures made. Constant-creative thinking happens when students compose the definitions as same as the number of images from the number of the concept built. Decrease-creative thought occurs if students produce definitions less in number than the number of pictures made. 


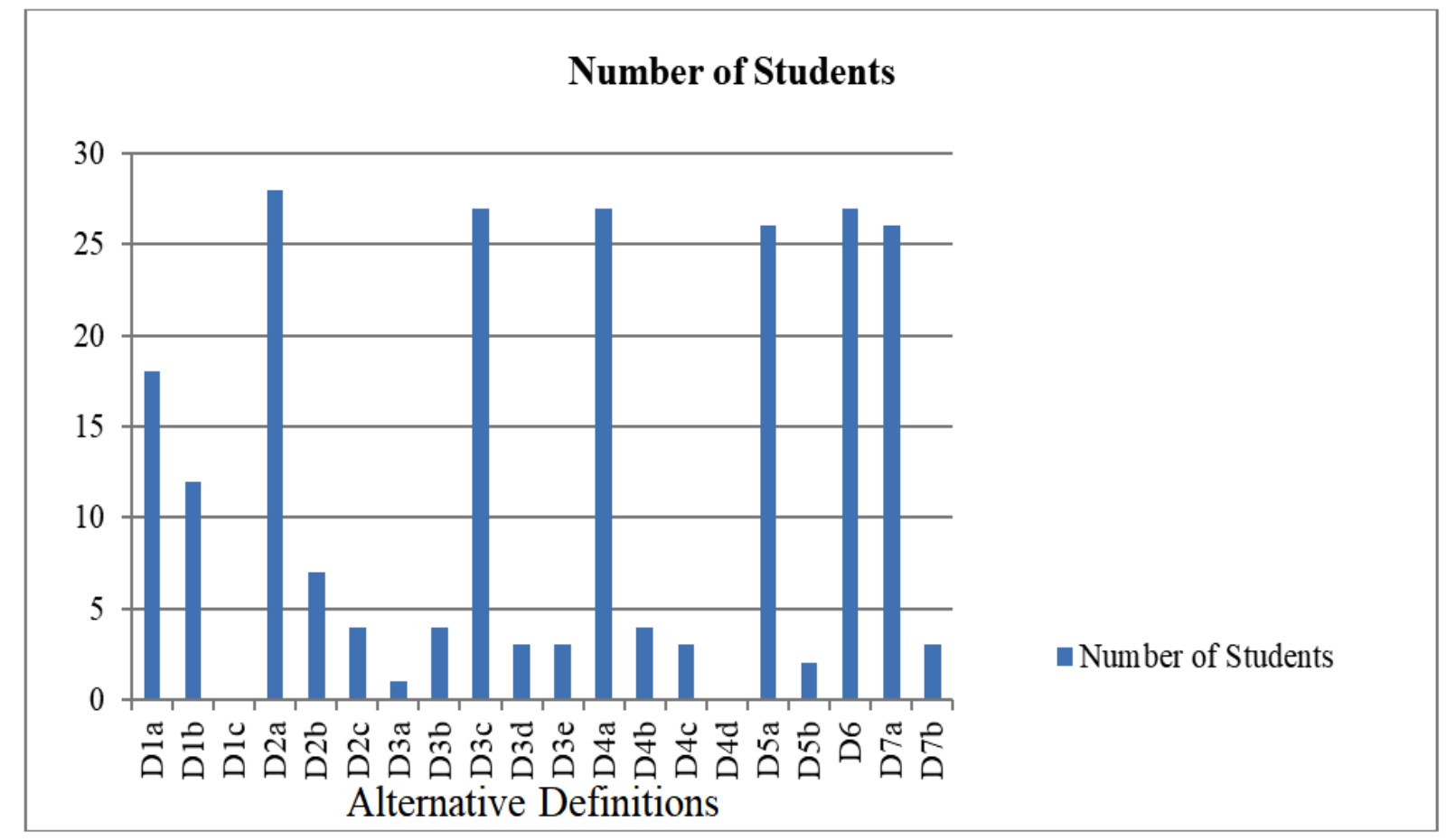

Figure 2. Students' frequencies number in defining alternative definitions

Table 3. Three group types of undergraduate students' creative thinking effects presented in black, red, and green colors numbers

\begin{tabular}{|c|c|c|c|c|c|c|c|c|c|c|c|c|c|c|c|c|c|c|c|c|c|c|c|c|c|c|c|c|}
\hline \multirow{2}{*}{ Students Findings } & \multicolumn{28}{|c|}{ Name of Students } \\
\hline & $\mathbf{A}$ & B & $\mathbf{C}$ & D & $\mathbf{E}$ & $\mathbf{F}$ & $\mathbf{G}$ & $\mathbf{H}$ & $\mathbf{I}$ & $\mathbf{J}$ & $\mathbf{K}$ & $\mathbf{L}$ & M & $\mathbf{N}$ & $\mathbf{O}$ & $\mathbf{P}$ & $\mathbf{Q}$ & $\mathbf{R}$ & $\mathbf{S}$ & $\mathbf{T}$ & $\mathbf{U}$ & $\mathbf{V}$ & W & $\mathbf{X}$ & $\mathbf{Y}$ & $\mathbf{Z}$ & $\mathbf{A A}$ & $\mathbf{A B}$ \\
\hline Elementary Objects & 14 & 8 & 7 & 9 & 9 & 10 & 9 & 5 & 9 & 11 & 10 & 7 & 15 & 8 & 14 & 9 & 6 & 12 & 14 & 14 & 12 & 10 & 8 & 8 & 9 & 8 & 15 & 7 \\
\hline $\begin{array}{c}\text { Alternative } \\
\text { Definitions } \\
\text { Number }\end{array}$ & 12 & 4 & 7 & 12 & 9 & 9 & 10 & 8 & 7 & 7 & 10 & 7 & 7 & 7 & 7 & 7 & 7 & 7 & 7 & 13 & 8 & 11 & 7 & 7 & 7 & 7 & 7 & 7 \\
\hline
\end{tabular}


Evaluating teacher candidate in creative thinking was discovered five students productive creative thought, five students with constant creative thought, and eighteen students with a decrease-creative idea. Hereafter, it presents the highlighted record and the interviews result of one student representing these groups, i.e., student $D$ for productive-creative thinking, student $L$ for constant-creative view, and student $\boldsymbol{A}$ decrease-creative thought.

\section{Student D}

In solving the line segment definition (Definition 2), student $D$ drew two pictures representing the line segment $A B$ (Figure 3). Afterward, he structured two definitions via these pictures. In the first stage, he stated that a line segment $A B$ is the points $A, B$, and the points between them, and in the second stage, a line segment $A B$ is a collection of points on the line that includes the point $A, B$, and all points between point $A$ and $B$. In the next moment, student $D$ could produce another definition by using a ray of line, i.e., the segment $A B$ is a collection of points on a ray $A B$ drawn from point $A$ to point $B$. The work results and interview records of student $D$ are presented as follows.

$D$ : In the beginning, i just thought of two definitions, namely, the definition of line segments $A B$ is as points $A, B$ and the points between them, and it is a collection of points on the line from point $A$ to $B$. Moreover, after $i$ reflect, a line segment can be obtained from line rays. Two definitions are 1) points $A, B$ and the points between them (between $A$ and $B$ ), 2) a collection of points on the line from point $A$ to $B$, and 3) a collection of points on a ray drawn from point $A$ to point $B$ is also called the line segment $A B$.

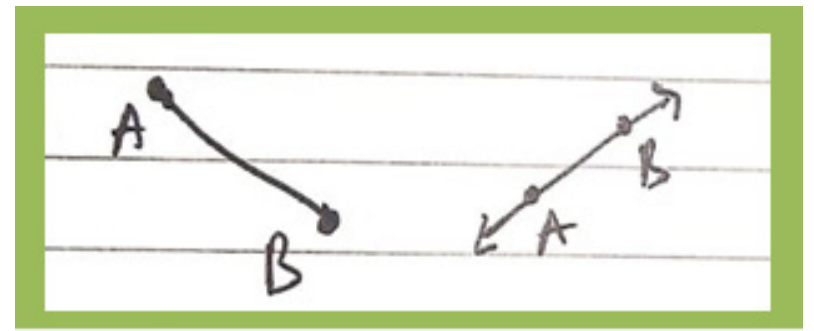

Figure 3. Work Results of Student D

\section{Student $L$}

Unlike student $D$, in defining the line segment, student $L$ made three pictures to show the line segment $A B$ (Figure 4). Using these pictures, he was successful in composing three definitions. The first stage was said that a line segment is a part of a line consists of two points $A, B$, and all points between $A$ and $B$. The second stage was explained that a line segment is a part of a ray with its endpoints $A$ and $B$. Then, the declaration of a line segment is two points $A, B$, and all points between $A$ and $B$ laid on a straight line. The work results and interview records of student $L$ are as follows.

$L:$ I arrange the definitions of those pictures from the data. The first definition of a line segment is a part of a line consists of two points $A, B$, and all points between $A$ and $B$. In the second definition, if there is a part of a line ray with endpoints $A$ and $B$. The third definition is two points $A, B$, and all points between $A$ and $B$ laid on a straight line.

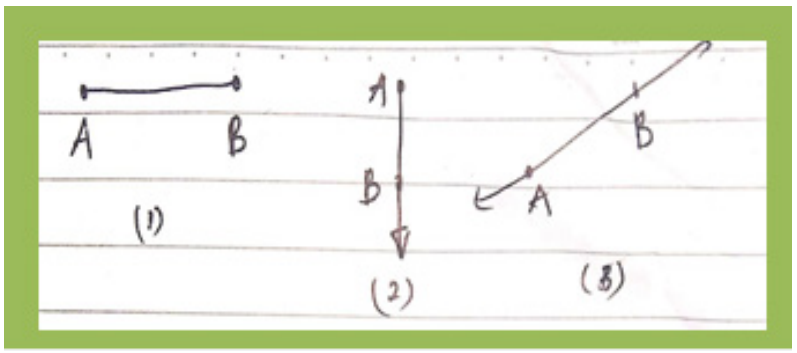

Figure 4. Work Results of Student $L$

\section{Student $\boldsymbol{A}$}

Student $\boldsymbol{A}$ made three pictures to show the line segment AB. Via these three pictures (Figure 5), he/she could produce two definitions. He/she said in the first definition as follows. Two points $A$ and $B$ are connected by a line from point $A$ to $B$ called a line segment $A B$. The second definition was said that a line segment $A B$ is the set of points $A, B$, and between them on the line $A B$. The work results and interview records of student $A$ are presented as follows.

A: The reasons from both definitions have represented the figures (a), (b), and (c). The first definition is two points $A$ and $B$ connected by a line from point $A$ to $B$. The second definition is that the set of points $A, B$, and between them on the line $A B$.

Tc: Represent, what does it mean?.

A: Due to, points $A$ and $B$ are both on lines (b) and (c); consequently, they are represented by the second definition.

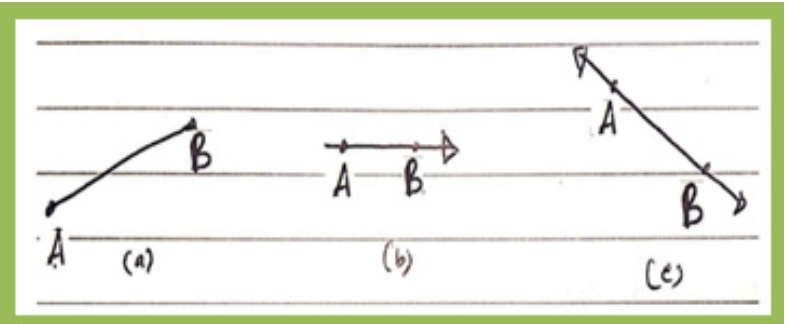

Figure 5. Work results of student $A$

\section{Conclusions}

Base on the research results and discussion, the students creatively could recognize and introduce each given 
geometry concept's elements in more than one picture. They could apply these primary objects of geometry and the made pictures to compose both descriptive and connotative definitions. The teacher candidates' creative efforts for recognizing some elementary objects of concept image encourage them to be aware and straightforward in understanding characteristics and properties of the geometry concepts. This approach also provides many ideas, methods and more effective to construct the geometry concepts in different ways and with students' own words.

Each student could generally create about eight alternative definitions of the seven provided definitions. $\mathrm{He} / \mathrm{she}$ could achieve six correct alternative definitions that met the necessary and sufficient criteria to define these concepts. Overall, the average score of the student achievement level was in the category almost perfect. They could choose adequate words with simple data. It also discovered that a few students failure to compose the sentences. On the other side, it revealed three group students of the creative thinking scheme in defining concepts, i.e., productive- creative, constant-creative, and decrease-creative thinking. It was found that ten students thought creatively productive and constant-creative idea, while eighteen students had a decrease-creative thought.

As previously introduced in this research about defining geometry concepts through the creative thinking approach, the exciting thing to discuss in the future is how the teacher candidate's students should be competent in explaining argumentations to prove geometry theorems in both direct and indirect proofs. They have to be capable of applying the procedure correctly and to be skillful in choosing axioms and theorems having relations with the proven theorems.

\section{Appendix 1}

\section{A. Course Material}

We prepared some primitive terms and seven definitions for the course material of this research that was usually applied in proving geometry theorems as follows.

- Set, point, line, plane, and between are undefined;
Five incidence axioms of line and plane;

- Definition 1: A ray $A B$ (noted $\overrightarrow{A B}$ ) is the set of points on a line that consists of the endpoint $A$ of the ray and all points on the same side of point $A$ that contains point $B$.

- Definition 2: A segment $\overline{A B}$ is the set of points $A, B$, and all points between points $A$ and $B$.

- The midpoint of a line segment is the point that divides the line segment into two equal parts.

- Definition 3: An angle is the union of two rays that share at a common endpoint.

- The bisector of an angle is the straight line that divides the angle into two equal angles.

The teacher candidate's students have to comprehend those geometry concepts, and they are given an explanation relating to Figures $6 a, 6 b, 6 c, 6 d, 6 e$, and $6 f$ that, respectively, describes the point $A$, the line $P Q$ noted $\overleftrightarrow{P Q}$, the plane $\alpha$, the ray $B C$, the line segment $A B$, and the angle $R S T$ noted $\angle R S T$.

- A polygon is a union of straight-line segments $\overline{P_{1} P_{2}}$, $\overline{P_{2} P_{3}}, \ldots, \overline{P_{n-1} P_{n}}, \overline{P_{n} P_{1}}$ that are constructed by the points $P_{1}, P_{2}, P_{3}, \ldots, P_{\mathrm{n}-1}, P_{\mathrm{n}}$ such that if two any segments intersect, then they meet precisely at one of the points $P_{1}, P_{2}, P_{3}, \ldots, P_{\mathrm{n}-1}, P_{\mathrm{n}}$.

- Definition 4: A triangle is a polygon of three sides.

- Two straight lines are said perpendicular if they intersect to form a pair of equal adjacent angles or form a right angle.

- Definition 5: An altitude of a triangle is a line segment from the triangle vertex, perpendicular to a line containing the opposite side of the vertex.

- Definition 6: A median of a triangle is a line segment joining the triangle vertex to the midpoint of the opposite side of that vertex.

- Definition 7: An angle bisector of a triangle is a line segment that bisects one of the angles, from the vertex to the opposite side of that angle.

Relating to the Definitions 4-7, Figures 7a, 7b, 7c, and $7 \mathrm{~d}$, respectively, describes the example of triangle $A B C$, the altitude line segment $\overline{A D_{1}}$, the median line segment $\overline{A D_{2}}$, and the angle bisector line segment $\overline{A D_{3}}$ of the triangle $A B C$.

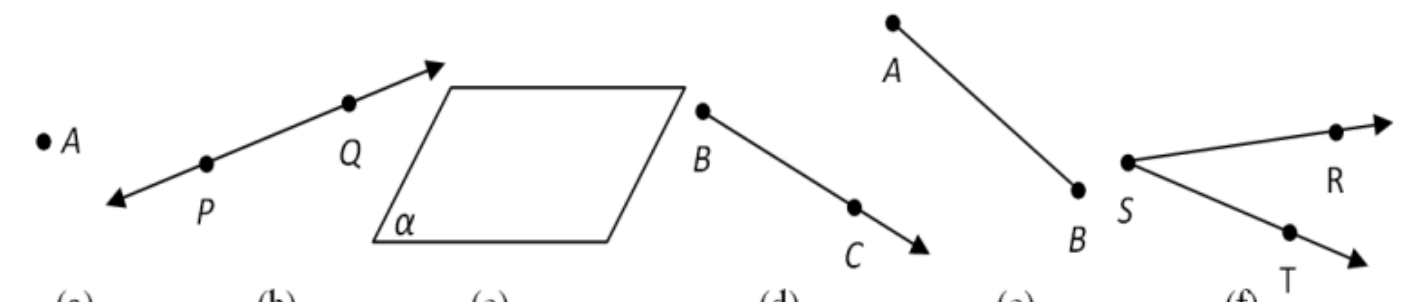

(a)

(b)

(c)

(d)

(e)

(f)

Figure 6. Some primitive and elementary pictures of geometry objects 


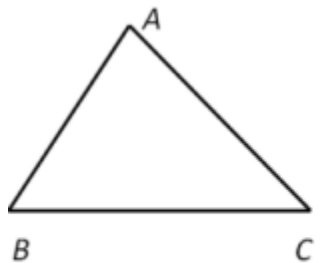

(a)

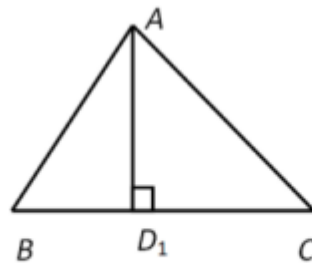

(b)

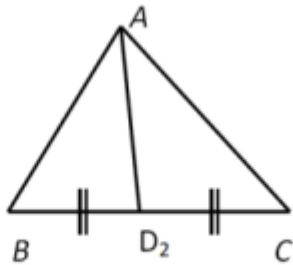

(c)

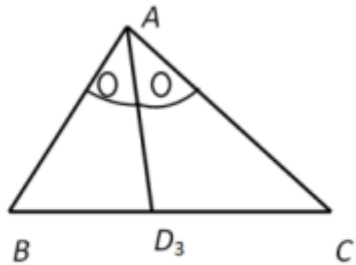

(d)

Figure 7. The triangle $A B C$ and connecting a line segment from vertex $A$ to the side $\overline{B C}$

\section{B. Item of Questions}

\section{Instruction: Answer these questions with clear sentences and straightforward.}

\section{Time: 150 minutes.}

a. For each of the following Definitions 1-7, determine the primitive and elementary objects of geometry that can construct a concept image of these definitions. Then, declare the number and name of needed geometry elements for each of the following definitions.

1. A ray $A B$ (noted $\overrightarrow{A B}$ ) is the set of points on a line that consists of the endpoint $A$ of the ray and all points on the same side of point $A$ that contains point $B$.

2. A segment $\overline{A B}$ is the set of points $A, B$, and all points between points $A$ and $B$.

3. An angle is the union of two rays that share at a common endpoint.

4. A triangle is a polygon of three sides.

5. An altitude of a triangle is a line segment from the triangle vertex, perpendicular to a line containing the opposite side of the vertex.

6. A median of a triangle is a line segment joining the triangle vertex to the midpoint of the opposite side of that vertex.

7. An angle bisector of a triangle is a line segment that bisects one of the angles, from the vertex to the opposite side of that angle.

b. Utilizing your finding primitive and elementary objects in task (a), draw and write how to construct the geometry concepts image for each pair of the basic objects. c. Compose some alternative definitions for Definitions 1-7 using your obtaining basic objects in the task (a) and the construction ways in the task (b) with your own words and different from these seven definition sentences.

\section{Appendix 2}

\section{Some Primitive and Elementary Objects from the Seven Formal Concepts}

Redefining Definitions 1-7 can use a descriptive form by using geometry minimal data (M1). We can also utilize a connotative definition by using geometry maximal data (genus) and differentiator (M2). For Definition 2, a geometry minimal data that meet the necessary and sufficient conditions of the line segment $\overline{A B}$ is enough points $A$ and $B$. In contrast, a geometry maximal data of the triangle definition is a polygon with the differentiator: three sides. From Definitions 1-7, in Figure 8 and Figure 9, we visually introduce some primitive and primary objects needed to compose some alternative definitions. The primitive and primary objects list with its code types of each Definition 1-7 are as follows.

\section{- Definition 1: A ray.}

Two points (Figure 8a-M $)$; a line (Figure $8 \mathrm{~b}-\mathrm{M}_{2}$ ).

\section{- Definition 2: A line segment}

Two points (Figure $\left.8 \mathrm{c}-\mathrm{M}_{1}\right)$; a ray $\left(\right.$ Figure $\left.8 \mathrm{~d}-\mathrm{M}_{2}\right)$; a line (Figure $8 \mathrm{e}-\mathrm{M}_{2}$ ).

\section{Definition 3: An angle}

Three points (Figure $8 \mathrm{f}-\mathrm{M}_{1}$ ); a point and a ray (Figure $\left.8 \mathrm{~g}-\mathrm{M}_{1}\right)$; two rays (Figure $8 \mathrm{~h}-\mathrm{M}_{1}$ ); a ray and a line (Figure $8 \mathrm{i}-\mathrm{M}_{1}$ ); two lines (Figure $8 \mathrm{j}-\mathrm{M}_{2}$ ). 


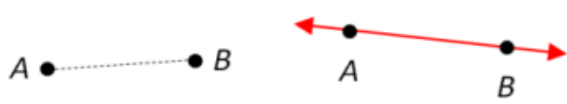

(a)

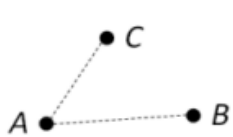

(f) (b)

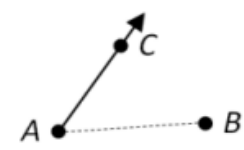

(g)

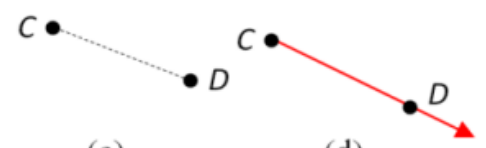

(d)

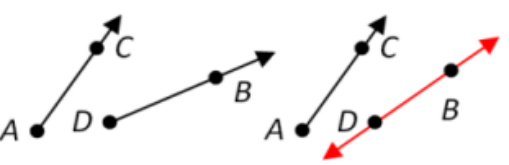

(h)

(i)
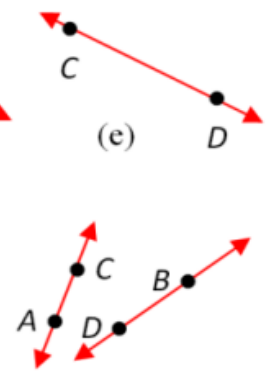

(j)

Figure 8. Elementary objects of geometry defining ray, line segment and an angle

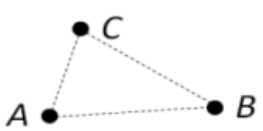

(a)

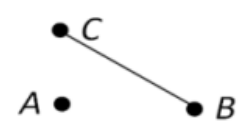

(b)

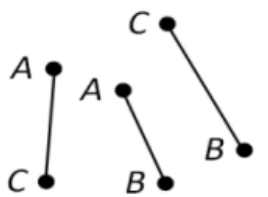

(c)

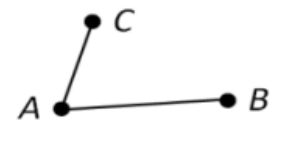

(d)

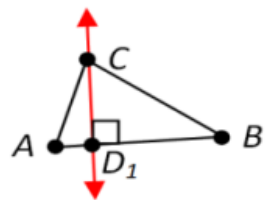

(e)

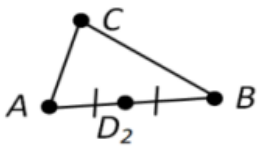

(f)

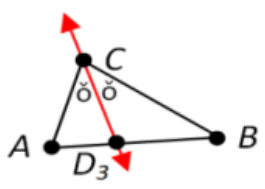

(g)

Figure 9. Elementary objects of geometry defining triangle, altitude, median, and angle bisector of a triangle

\section{- Definition 4: A triangle}

Three points not on a line (Figure $\left.9 \mathrm{a}-\mathrm{M}_{1}\right)$; a point and a line segment not collinear (Figure 9b- $\mathrm{M}_{1}$ ); three line segments with the length measure of any one segment less than the sum length measure of the others (Figure 9c-M $\mathrm{M}_{1}$; an angle that is constructed by two line segments from a measure between 0 and 180 degrees $\left(9 \mathrm{~d}-\mathrm{M}_{1}\right)$.

\section{- Definition 5: An altitude of a triangle $A B C$}

One vertex of $A, B$, or $C$ and a line pass to this vertex and perpendicular this opposite side of the triangle $A B C$ (Figure 9e-M2).

\section{- Definition 6: A median of a triangle $A B C$}

One vertex of $A, B$, or $C$ and the midpoint of the opposite side to this vertex of the triangle $A B C$ (Figure 9f-M1).

\section{- Definition 7: An angle bisector of a triangle $A B C$}

One vertex of $A, B$, or $C$ and an angle bisector of the triangle $A B C$ that pass this vertex (Figure 9g-M2).

\section{REFERENCES}

[1] A. Kuzniak, P. R. Richard, P. M. Chrysanthou. From Geometrical Thinking to Geometrical Working Competencies. Developing Research in Mathematics Education. TJ International Ltd, Great Briatain, 2018.
[2] J. Fisher. Geometric Thinking Concept Map. Published on Assessment Resource Banks. Retrieved February, 12, 2020, from https://arbs.nzcer.org.nz.

[3] Info Menarik, Penasaran dengan Hasil UKG Kemendikbud. Retrieved December 15, 2019, from https://info-menarik.net/ hasil-ukg-kemendikbud-tahun-2015.

[4] S. Yunus. Mengkritisi Kompetensi Guru, detiknews Jumat 24 November 2017. Retrieved January 20, 2020, from https://news.detik.com/kolom/3741162/ mengkritisi-kompeten si-guru.

[5] Organization for Economic Cooperation and Development (OECD). Program for International Student Assesment (PISA) Results from PISA 2015, Indonesia, Retrieved March 1, 2019.

[6] National Center for Education Statistics (NCES). International Outcomes of Learning in Mathematics Literacy and Problem Solving (pp.5). U.S. Department of Education, Institute of Education Sciences, NCES, 2004.

[7] Republika. Nilai Matematika Paling Turun pada UN 2016 ? Retrieved March 15, 2019, https://www.republika.co.id/ berita/pendidikan/eduaction/16/06/1.

[8] S. Maharani, T. Nusantara, A. R. As'ari, A. Qohar Analyticity and Systematicity Students of Mathematics Education on Solving Non-routine Problems, Math. and Stat., Vol. 7(2), 50-55, 2019.

[9] Kementerian Pendidikan dan Kebudayaan Republik Indonesia (Kemendikbud). Capaian Nasional Tahun Pelajaran 2019, Pusat Penilaian Pendidikan, 
https://hasilun.puspendik.kemdikbud.go.id.

[10] O. Zaslavsky, K. Shir. Students' Conceptions of a Mathematical Definition, Journal for Research in Mathematics Education, Vol. 36(4), 317-346, 2005.

[11] P. Herbat, G. Gonzalez, M. Macke. How Can Geometry Students Understand, What it Means to Define in Mathematics?, The Mathematics Educator, Vol. 15(2), 17-24, 2005.

[12] M. De Villiers. To Teach Definition in Geometry or Teach to Define?, ResearchGat. Retrieved January 5, 2020, from https://www.researchgate.net/ publication/255605686.

[13] M. Kallia, S. Panagiotis. The Role of Teaching in the Development of Basic Concepts in Geometry: How the Concept of Similarity and Intuitive Knowledge Affect Student's Perception of Similar Shapes, in Proceedings of CERME 6, 736-745, January 28th-February 1st 2009, Lyon France (C) INRP 2010, 2009.

[14] R. F. Cunningham, A. Roberts. Reducing the Mismatch of Geometry Concept Definitions and Concept Images Held by Pre-Service Teachers, IUMPST: The Journal 1, www.k - 12prep.math.ttu.edu, 2010.

[15] T. M. Salinas, K. Lynch-Davis, K. J. Mawhinney, D. A. Crocker. Exploring quadrilaterals to reveal teachers' use of definitions: Results and implications, Australian Senior Mathematics Journal, Vol. 28(2), 2014.

[16] D. K. Yadav. Exact Definition of Mathematics. International Research Journal of Mathematics, Engineering and IT, Vol. 4(1), 2017.

[17] S.A. Chamberlin, S.M. Moon. Model-eliciting activities as tool to develop and identify creativity gifted mathematicians, Journal of Secondary Gifted Education, Vol. 17(1), 37-47, 2005.

[18] M. Koloroutis. Relationships-Based care (A Model for Transforming Practise), Creative Health Care Management Inc., Minneapolis, 2004.

[19] Harris, R. (2012). Introduction to Creative Thinking. Retrieved January 15, 2020, https://www.virtualsalt.com/crebook1.htm.

[20] B. Birgili. Creative and Critical Thinking Skills in Problem-based Learning Environments, Journal of Gifted Education and Creativity, Vol. 2(2), 71-80, 2015.

[21] K. J. Gilhooly, L. J. Ball, L. Macchi. Insight and creative thinking processes: Routine and special. Thinking \&
Reasoning, Vol. 21(1), 1-4, 2015.

[22] J. B. N. Nakin. Creativity and Divergent Thinking in Geometry Education (Didactics Disertation). University of South Africa, 2003.

[23] Q. Dan, J. Xie. Mathematical Modelling Skills and Creative Thinking Levels: An Experimental Study, in Proceedings of the 14th international conference on the teaching of mathematical modelling and applications (pp.457-466). ICTMA, Hamburg, Germany, July 27-31, 2009, ResearchGate, 2011.

[24] M. Nadjafikhah, N. Yaftian, S. Bakhshalizadeh. Mathematical creativity: some definitions and characteristics, in Procedia-Social and Behavioral Sciences $31,2012$.

[25] J. Grégoire. Understanding Creativity in Mathematics for Improving Mathematical Education, Journal of Cognitive Education and Psychology, Vol. 15(1), 24-36, 2016.

[26] L. J. Sheffield. Mathematical Creativity and Mathematical Giftedness. ICME-13 Monographs, Springer, 2018.

[27] M. Rhodes. An Analysis of Creativity. Phi Delta Kappan, 1961.

[28] H. Nassaji. Qualitative and descriptive research: Data type versus data analysis, Language Teaching Research, Vol. 19(2), 129-132, 2015.

[29] H. Lewis. Geometry a Contemporary Course. Van Nostrand, Princeton, 1968.

[30] R. D. Gustafson, P. D. Frisk. Elementary Geometry. JWS, Inc., New York, 1991.

[31] B. Rich, C. Thomas. Geometry, Schaum's Outline Series. Mc Graw Hill, New York, 2009.

[32] D. C. Alexander, G.M. Koeberlein. Elementary Geometry for College Students. Brooks/Cole, Belmont, USA, 2011.

[33] E. Fischbein, The Theory of Figural Concepts, Educational Studies in Mathematics, Vol. 24(2), 139-162, 1993.

[34] DCU Student Learning Resources. Learning to Learn: Creative Thinking and Critical Thinking. Office of the Vice-President for Learning Innovation and Registrar (Compiled by Ann Coughlan), 2007.

[35] M., A. Mariotti. Images and Concepts in Geometrical Reasoning (Expoiting Mental Imagery with Computer in Mathematics Education). NATO ASI Series, Springer, 1995. 